\title{
On the Megalithic Sites of the Gurage Highlands: A Study of Enigmatic Nature of Engravings and Megalith Builders ${ }^{1}$
}

\author{
Worku Derara *
}

\begin{abstract}
The megalithic culture in Ethiopia consists of stelae, dolmens, and tumuli which are extensively distributed throughout the country. Compared to the extent of the distribution, however, the initial tasks of methodical survey and locating them have been conducted relatively less. As part of the ventures in megalithic studies, this inventory was aimed at identifying, locating and describing megalithic sites in the Gurage highlands, principally those in the districts of Sodo and Mehur-Aklil. The investigation has unearthed the existence of a montage of megalithic culture, comprising tambourines associated with a tumulus and decorated flat stelae in Sodo, and dressed but undecorated stelae of such diverse shape as flat, rectangular, pentagonal and cylindrical in Mehur-Aklil. The decorated stelae in Sodo bear engravings representing humans, daggers and some other enigmatic decorations with symbolic significance hitherto unknown. Ethnographic data may help to arrive at a plausible meaning signified by the representations engraved on these stelae. Aside from the problems related to the meanings of symbols, it is quite difficult to establish relative chronology of the sites based on technological variation centering on the level of refinement.
\end{abstract}

Keywords :Ethiopia, Gurage Highlands, Sodo, Mehur-Aklil, Megalithic, Stela, Dolmen, Tumulus

\section{Introduction}

The Ethiopian megalithic tradition has been studied since the early years of the $20^{\text {th }}$ century. Yet, attempts to relate it to traditions in other regions have ended with no appreciable gains (Anfray 1982). Literature on the megalithic tradition of Ethiopia also shows a wider distribution of the tradition. However, the task of systematic survey and studies seems to have been carried out relatively less than the problem demands.

\footnotetext{
${ }^{1}$ This is a brief article based on an unpublished research conducted by the author in the Gurage highlands.

* Lecturer, Department of Archaeology and Heritage Management, Addis Ababa University
} 
Owing to its long tradition of erecting monuments, Ethiopia is regarded as a land of megalithic culture (Crawford 1954; Joussaume 1974, 1987). The varieties of megalithic monuments comprised within the Ethiopian megalithic culture fall into three major groups, dolmens, tumuli and stelae (Joussaume 1974).

The Southern part of Ethiopia is noted for its large number of megalithic sites. Estimates by Azais in the 1920s show the presence of about 10,000 stelae in Sidamo (Joussaume 1976a; Anfray 1982). Further research undertakings yielding valuable information on the megalithic tradition in Southern Ethiopia were conducted by Francis Anfray, who carried out excavation at Gatira Demma in 1976 (Anfray 1982) and Joussaume, who worked at Tiya between 1989 and 1992 (Joussaume 1995). Moreover, additional research activities during the 1970s and 1980s by the Institute of Ethiopian Archaeology and in the 1990s by Authority for Research and Conservation of Cultural Heritage (ARCCH) resulted in the identification of new sites and investigation of regional variants (Tekle 2001).

The megalithic sites covered by this inventory exhibit a tradition characterized by stelae, tambourines associated with burial mounds and clusters of buried stelae with irregular edges and different arrangements. The stelae in the study areas are generally regarded as Ya Gragn Dingay (literally the stones of Gragn). In Sodo, the association of the stelae with burials has been confirmed by excavations at Tiya (Joussaume 1995) and Gatira Demma (Anfray 1982), which according to these sources were dated between the $11^{\text {th }}$ and $13^{\text {th }}$ century to the $12^{\text {th }}$ century A.D respectively.

By and large, the volume of research on megalithic culture in Ethiopia can be considered as meager. Yet, recent archaeological investigations have increased our understanding about the type and distribution of megaliths in different parts of the country. These include inventory works conducted by the author in Gurage highlands in $2006^{2}$, archaeological surveys of megalithic sites in Chalba-Tutti of Gedeo Zone (Abiyot 2006), and Atsebi Wemberta district (Yohannes 2008), ethno archaeological study of megalithic tradition among Hadiya in Southern Ethiopia (Addisalem 2009) and archaeological study of megalithic sites in Aksum and Shire areas (Brhan 2010).

\section{The Study Areas, Data Acquisition and Methods of Analysis}

This archaeological inventory on the megalithic sites in Gurage highlands was conducted on fourteen sites located in two districts, notably Sodo and Mehur-Aklil. The towns of Bui and Hawariat serve as the administrative centers of the districts

\footnotetext{
${ }^{2}$ No further archaeological studies have so far been carried out since the author's work in Gurage highlands.
} 
of Sodo and Mehur-Aklil respectively. The study areas fall within what William Shack (1966) called "Gurageland", which covers the land between $37^{\circ} 30^{\prime}$ ' and $38^{\circ}$ $50^{\prime} \mathrm{E}$ and $7^{\circ} 46^{\prime}$ and $8^{\circ} 48^{\prime} \mathrm{N}$ (Muluneh 1994). Today, it is part of what is known as the Southern Nations Nationalities and Peoples (SNNP).

Map I. Map of the Study Areas

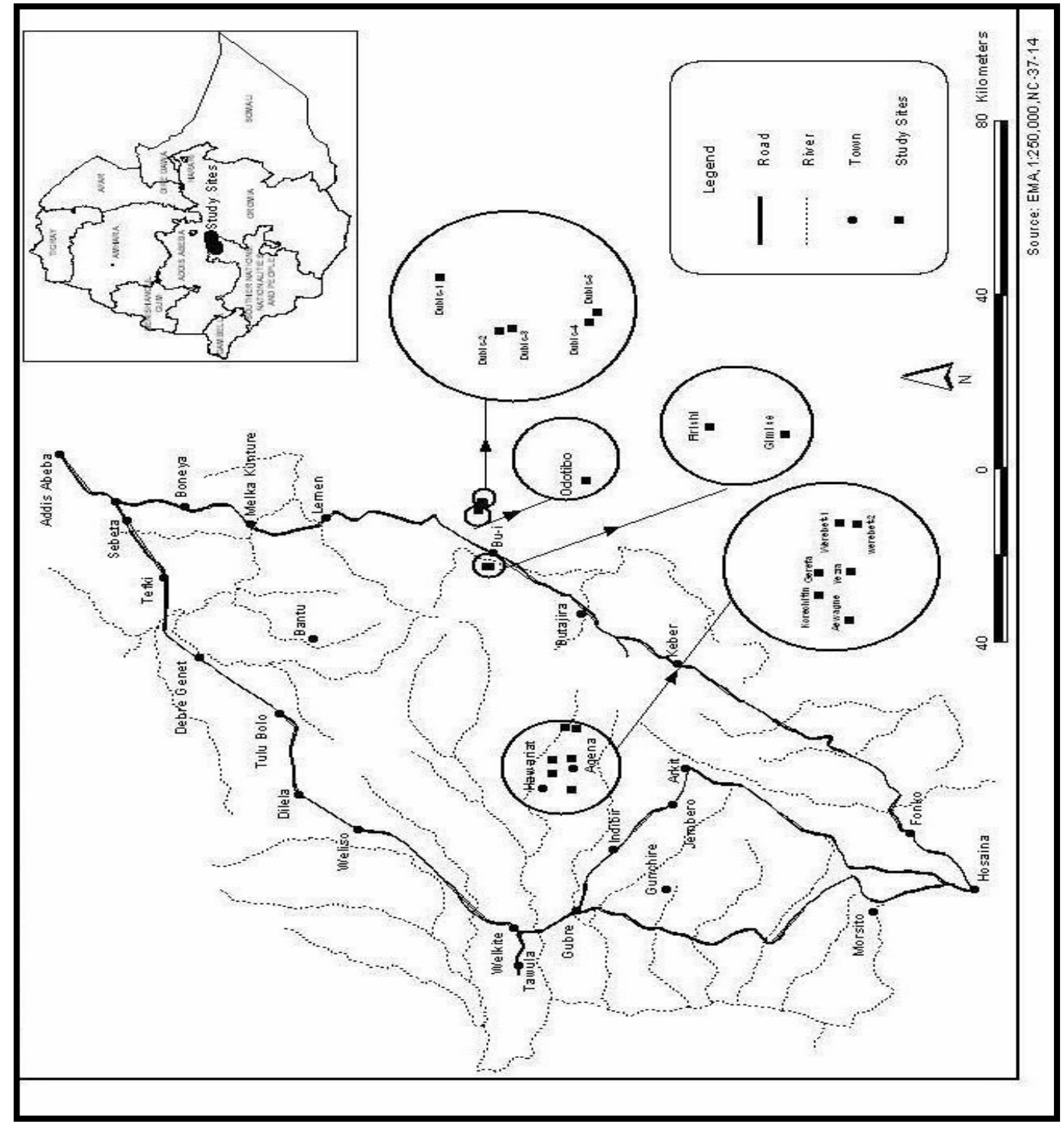


The study areas share the general geologic structure common to the south western central highland plateau. It is also reported that surface rock of the study areas is predominantly of volcanic origin of Pleistocene (Merla, et. al 1979). According to this source, outcrops of fero-basalts occur in the surroundings of Wolkite, whereas trachytes and rhyolites occur in parts of Sodo. In connection with this, abundant outcrops of rhyolites in Sodo and trachytes in Mehur-Aklil have been observed. In some cases, lithic outcrops resembling the stelae in the study areas have also been identified. Thus, the geological formations in the area seem to have provided a fertile ground for building the megaliths.

Information about the presence of megalithic sites in the study areas was obtained through my personal communication with professionals at the Authority for Research and Conservation of Cultural Heritage (ARCCH) and the Regional Bureau of Information and Culture. After conducting a preliminary visit to the study areas in November 2005, it was possible to ascertain the number and types of megalithic sites. Additional megalithic sites were also identified during my fieldwork in May 2006. Moreover, a further ground reconnaissance was conducted to identify and locate more sites and features relevant to the study.

In writing this paper both primary and secondary sources were employed. Data collected from the field was systematically organized to produce the summarized results of the study. In due course, both qualitative and quantitative methods were applied.

The classification of artifacts into types and subtypes based on qualitative, quantitative, morphological, technological and functional attributes is often indispensable in the formation of chronologies and culture history (Bahn 2001). Thus, to classify the megalithic sites in the study areas, a careful field observation was carried out to see similarities and differences in morphology and decoration of the stelae. In classifying the stelae in the study areas, I adopted the models used by Anfray (1982) and Joussaume (1993; 1995), who described the stelae in Gurage zone based on shape and surface attributes. Hence, classification in this paper is carried out based on such attributes as decoration and shape. The typological differences presented at site level have also helped to see the place of the sites within the regional variants classified by Joussaume in the early part of the 1990's (see Joussaume 1993).

\section{Distribution of Megalithic Sites and Types of Stelae}

The inventory has resulted in the discovery of a mosaic megalithic culture at fourteen sites located in six localities of the districts of Sodo and Mehur-Aklil. Attitudinal variation of the sites ranges between 1986 meters in Sodo to 2723 
meters in Mehur-Aklil. Eight of these megalithic sites are found in four localities situated to the east and west of the Bui town in the district of Sodo.

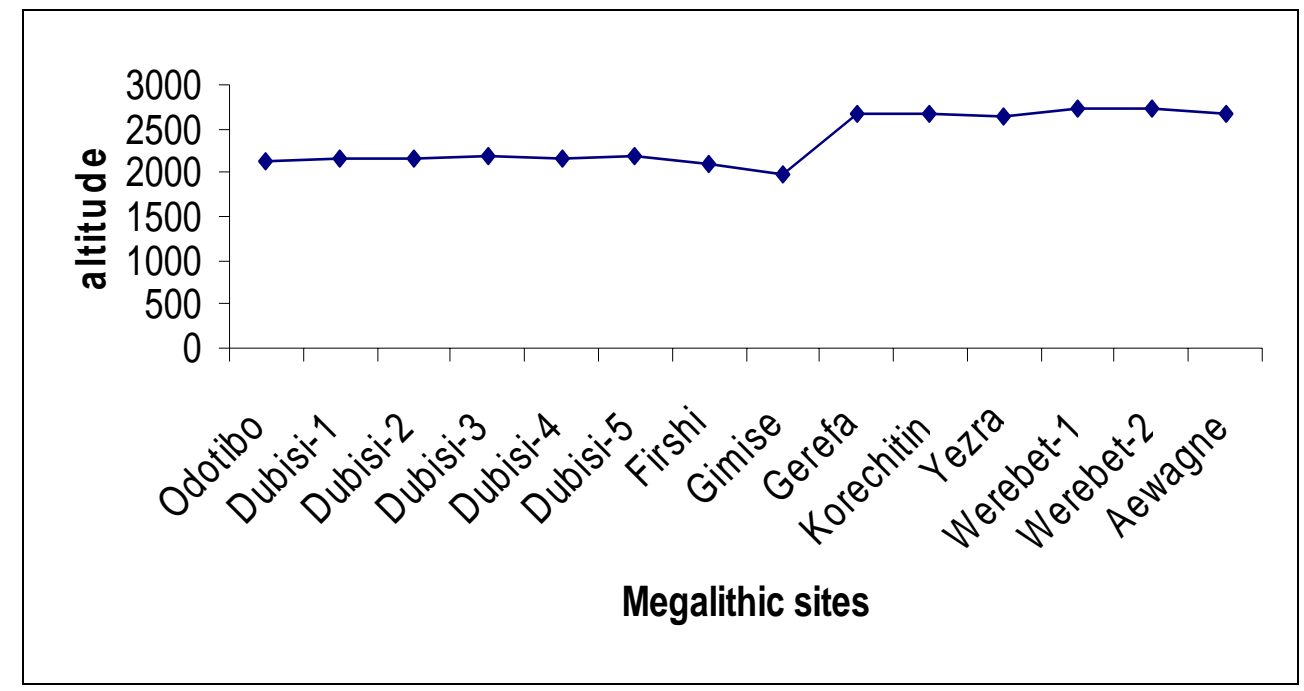

Graph I. Altitudinal distribution of megalithic sites in the study areas

The presence of megalithic structures in these areas can, generally, be considered as one of the constituents indicating permanent settlement. Especially, the location of the sites in areas with water supply, farmland and a defensive position (highland) suggest that settlement was not a haphazard business and that these factors were important in selecting a site for habitation.

The study has also attested the presence of twelve decorated stelae at five sites in Sodo, twelve dressed but undecorated stelae at six sites in Mehur-Aklil. The stelae in Mehur- Aklil occur in such varying shapes as flat, rectangular, pentagonal and cylindrical. The stelae in the study area also show variation in size ranging between $35 \mathrm{~cm}$ at Korechiten in Mehur-Aklil to $260 \mathrm{~cm}$ at Odotibo in Sodo. 
Table.1. Summary of decorated stelae at five sites in Sodo

\begin{tabular}{|c|c|c|c|c|c|}
\hline $\begin{array}{l}\text { Name of } \\
\text { Sites }\end{array}$ & \multicolumn{2}{|c|}{$\begin{array}{l}\text { Number of decorated } \\
\text { stelae at each sites }\end{array}$} & Height & Breadth & Remark \\
\hline \multirow[t]{3}{*}{ Odotibo } & \multirow[t]{3}{*}{3} & $\begin{array}{l}\text { Stela } \\
\text { No.1 }\end{array}$ & $220 \mathrm{~cm}$ & $72 \mathrm{~cm}$ & \multirow{3}{*}{$\begin{array}{l}\text { All of the stelae show } \\
\text { anthromorphic } \\
\text { representations, daggers, } \\
\text { two circles and "w" like } \\
\text { decorations. }\end{array}$} \\
\hline & & $\begin{array}{l}\text { Stela } \\
\text { No.2 }\end{array}$ & $260 \mathrm{~cm}$ & $91 \mathrm{~cm}$ & \\
\hline & & $\begin{array}{l}\text { Stela } \\
\text { No.3 }\end{array}$ & $200 \mathrm{~cm}$ & $103 \mathrm{~cm}$ & \\
\hline \multirow{5}{*}{$\begin{array}{l}\text { Dubis 1, } \\
\text { Locus } \\
\text { A }\end{array}$} & \multirow{2}{*}{$\begin{array}{c}2 \\
\text { in } \\
\text { Group } 1\end{array}$} & $\begin{array}{l}\text { Stela } \\
\text { No.1 }\end{array}$ & $70 \mathrm{~cm}$ & $80 \mathrm{~cm}$ & \multirow{5}{*}{$\begin{array}{l}\text { The stelae show differen } \\
\text { types of decorations. } \\
\text { Four of them have two } \\
\text { types of decorations } \\
\text { common to them. }\end{array}$} \\
\hline & & $\begin{array}{l}\text { Stela } \\
\text { No.2 }\end{array}$ & $70 \mathrm{~cm}$ & $83 \mathrm{~cm}$ & \\
\hline & \multirow{3}{*}{$\begin{array}{c}3 \\
\text { in } \\
\text { Group } 2\end{array}$} & $\begin{array}{l}\text { Stela } \\
\text { No.1 }\end{array}$ & $48 \mathrm{~cm}$ & $90 \mathrm{~cm}$ & \\
\hline & & $\begin{array}{l}\text { Stela } \\
\text { No.2 } \\
\end{array}$ & $56 \mathrm{~cm}$ & $112 \mathrm{~cm}$ & \\
\hline & & $\begin{array}{l}\text { Stela } \\
\text { No.3 }\end{array}$ & $37 \mathrm{~cm}$ & $52 \mathrm{~cm}$ & \\
\hline Dubis 2 & \multicolumn{2}{|l|}{1} & $29 \mathrm{~cm}$ & 53ccm & $\begin{array}{l}\text { The stela at this site is } \\
\text { decorated with unknown } \\
\text { geometric lines radiating } \\
\text { from disc like engraving } \\
\text { close to the base of the } \\
\text { stela. }\end{array}$ \\
\hline Firshi & \multicolumn{2}{|l|}{1} & $63 \mathrm{~cm}$ & $86 \mathrm{~cm}$ & $\begin{array}{l}\text { It is decorated with } \\
\text { engravings of daggers } \\
\text { and unknown engravings }\end{array}$ \\
\hline \multirow[t]{2}{*}{ Gimise } & 2 & $\begin{array}{l}\text { Stela } \\
\text { No.1 }\end{array}$ & $53 \mathrm{~cm}$ & $83 \mathrm{~cm}$ & \multirow{2}{*}{$\begin{array}{l}\text { Both are decorated with } \\
\text { a representation of a } \\
\text { branch of a certain plant, } \\
\text { probably Enset. Stela } \\
\text { No. } 1 \text { is unique for it } \\
\text { displays a zoomorphic } \\
\text { engraving. }\end{array}$} \\
\hline & & $\begin{array}{l}\text { Stela } \\
\text { No. } 2\end{array}$ & $260 \mathrm{~cm}$ & $90 \mathrm{~cm}$ & \\
\hline
\end{tabular}


From typological point of view, the decorated stelae at Odotibo and Dubis locality show characteristic features typical of the Southern variants ${ }^{3}$. Particularly, the stelae at Odotibo comprising of flat stelae decorated with daggers, two circular disc shaped engravings, and engravings resembling the English alphabet "W" in a reversed position and the stela at Firshi, decorated with daggers and other geometric representations, fall within the same variants. Hence, they exhibit characteristic features of both the first and the second group within the Southern variants. Although both stelae from Gimise show characteristic features noticeable on the stela at Firshi, stela №.1 is unique as it is the only of the stelae engraved with a zoomorphic representation.

\section{Symbols and Their Meaning}

Symbols are used for regulating and organizing people as well as the material world. They may simply convey information from one person to another and from one point of time to another. They can signify power, social organization or cult systems, or the economy of a given society (Renfrew and Bahn 1996). Accordingly, the engravings on the decorated stelae at sites located in Sodo are not without symbolic significance. Some of the representations can easily be identified, while others have largely remained enigmatic to this day.

\footnotetext{
${ }^{3}$ Joussame (1993) classified the stelae in Southern Ethiopia into two regional variants, the Southern variants and the Northern variants. According to him, the Southern variants extend from Sodo up to Dobbi and embrace those in Meskan and Silti. Within this category, he distinguished five major types of stelae. The first type consists of flat stelae depicting daggers, arc, and geometric and human representations. The second type comprises of anthromorphic stelae with depictions of human chest and reversed " $\mathrm{X}$ " and "W" and two circles. The third types are cylindrical stelae with size ranging between $0.5 \mathrm{~m}$ and $1.80 \mathrm{~m}$ high. The fourth and the fifth types of stelae are phallic and hemispherical/conical/respectively.
} 


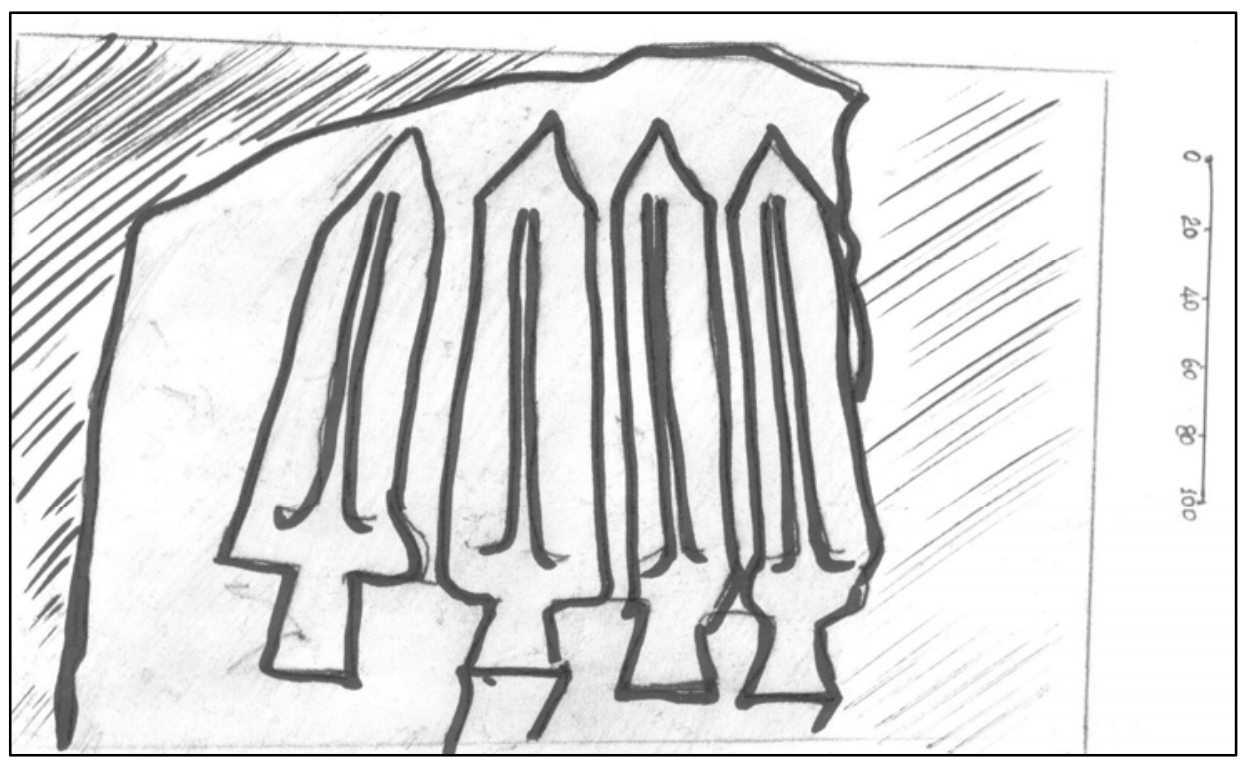

Figure 1: Daggers engraved on stela №.2 at Odotibo

Engravings of daggers on the fallen stelae at Odotibo and on those at Firshi suggest the use of metal weapons and hence could be interpreted as symbolizing a burial of a warrior or hunter. Though it is dubious and debatable, the number of engraved daggers could possibly indicate the rank of the warrior or the number of enemies killed.

At Odotibo, engravings resembling the English alphabet "W" in a reversed position occur individually or doubled positioned back to back on stela №.2 and stela No.1 respectively. But, the symbolism of this decoration is not clear. As noted by Anfray (1982), this representation has remained mysterious because no plausible explanation can be given. 


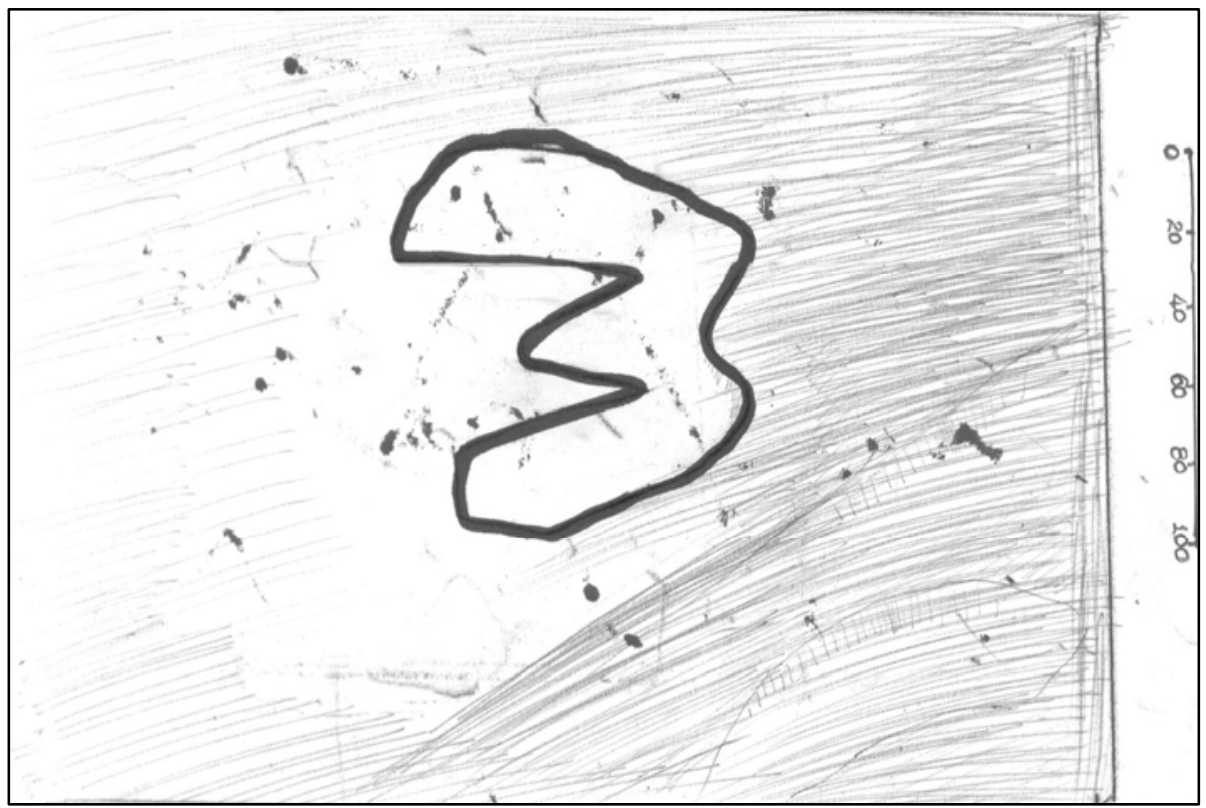

Figure 2: A reversed 'W' on stela No.1 at Odotibo

Even much more enigmatic is the engraving with the rectangular base and branched pillar resting on the base. This decoration is visible on the fallen stela №.1 and stela №.2 at Odotibo. In connection with this depiction, there are different plausible but still controversial views. As stated by Anfray (1982), it could be a branch of a tree. One possible interpretation is that an engraving of a tree could be represented to signify its ritual significance in a society. Anfray also states that it is also considered as a projective weapon like a spear or even may be regarded as a representation of a branched stick held by the pilgrims of Dire Sheik Hussien. Though the branches at the top resemble the stick often called Dhanquu, the rectangular base cannot be correlated with the pointed metal called Ankase, which is attached at the base of the stick held by the pilgrims. 


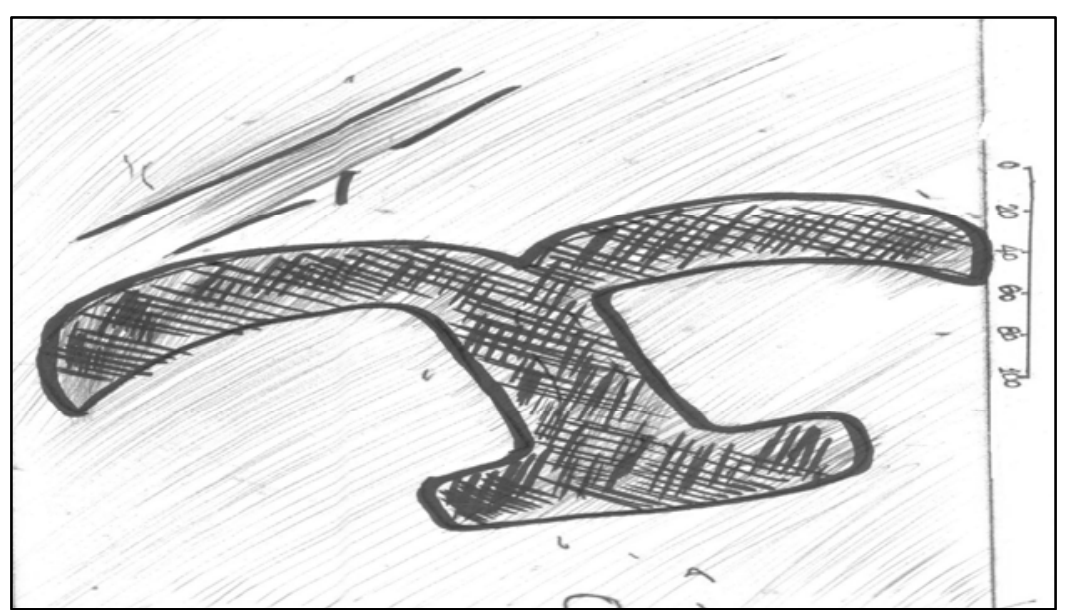

Figure 3: One of the enigmatic decorations engraved on stela №.1 and stela No.2 at Odotibo

As regards the above engraving, Joussaume (1995) related it with similar decorative scarifications of the Anguwak people living in Southern Sudan. In connection with this representation, the oral information from the area, which is widely accepted, suggests that it symbolizes the traditional wooden headrest ${ }^{4}$.

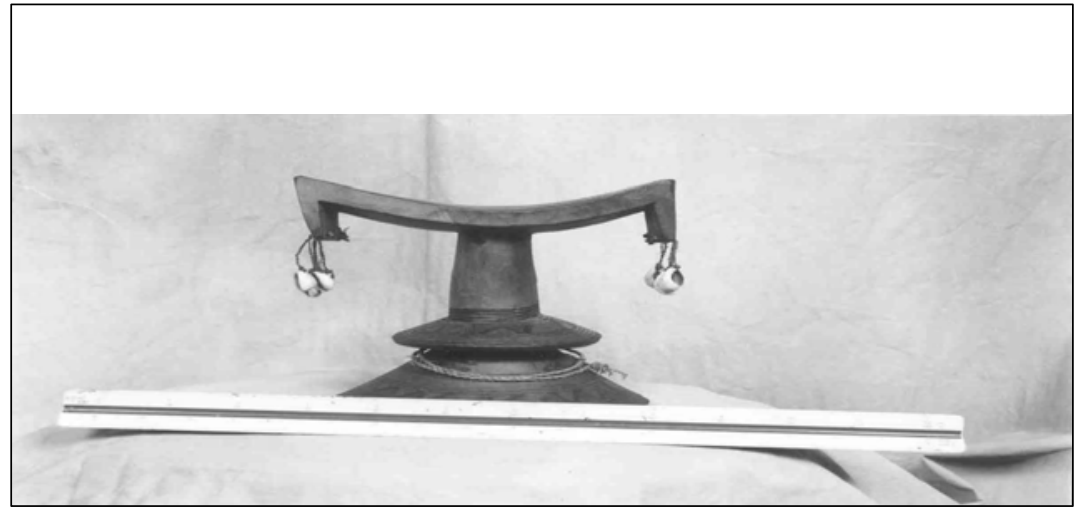

Figure 4: Wooden headrest from Odotibo, Sodo

${ }^{4}$ Ehret (2002) states that neck rests, carved out of wood, were invented by middle Nile peoples of the Sudanic civilization before 5000BCE and spread from Sudanic Peoples to Cushites of the Horn of Africa during or after the first millennium B.C. 
This wooden headrest, locally called Gime ${ }^{5}$, is widely used over most part of Southern Ethiopia. However, due to the morphological differences between the representation and the wooden headrest, it cannot be reported as a representative of the headrest.

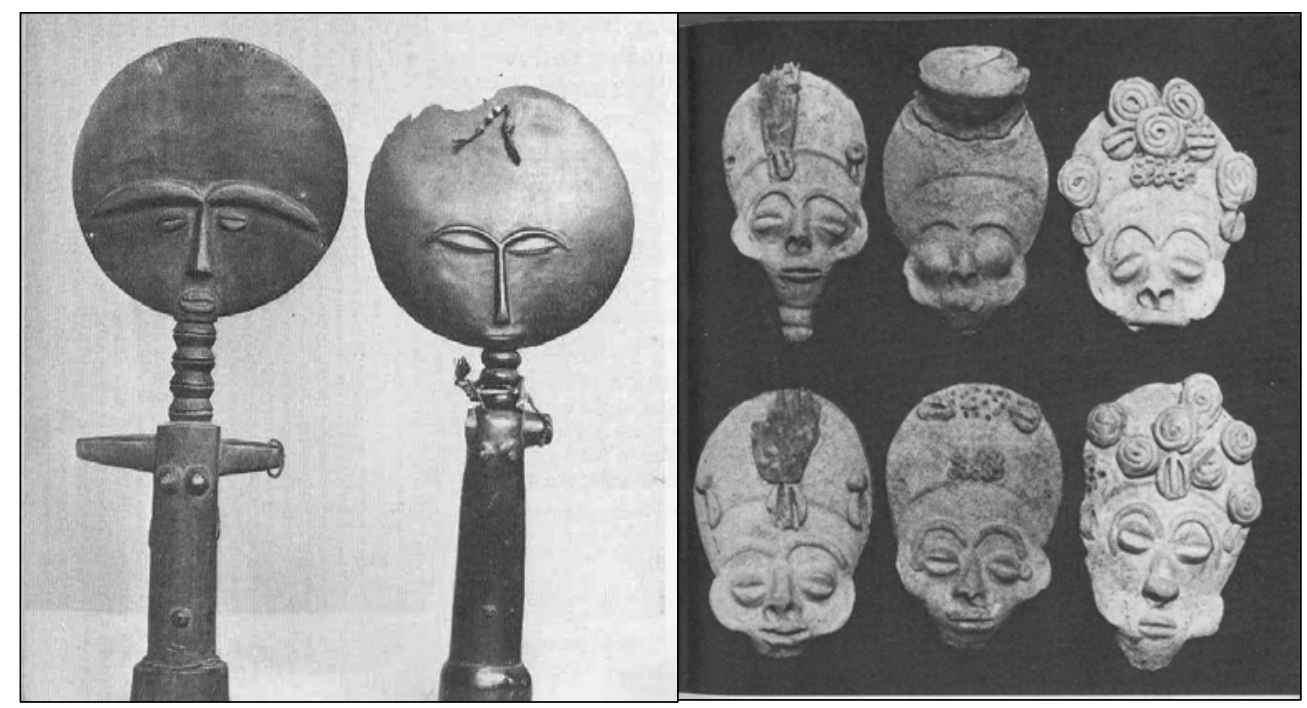

Figure 5: Terracotta heads (Left) excavated by Dr.Oliver Davie at Shinsan, Southern Ashanti. These sculptures date from the late $16^{\text {th }}$ century and $17^{\text {th }}$ century. Two akua mma dolls (Right) from Ashanti, which express Ashanti ideal beauty

Source: After Willett, .F., 1971

Although it seems difficult to make analogies with similar decorations found outside Ethiopia, attempts to examine comparable parallels might help to look into the meaning of this unknown decoration within the context of African art and

\footnotetext{
${ }^{5}$ It is a wooden neck rest made by wood workers in Sodo to serve as a pillow. Regarding this, informants repeatedly assert that it was made and used in earlier days long before the introduction of modern pillow made of cotton. Even now Gime is still in use amidst the people of Sodo and is especially important in the gift system as it is presented by parents of a young man to a girl married to him.
} 
hence this might shed light on the problems related to the mystery behind this representation.

The representations above raise questions about those decorative engravings on the stelae at Odotibo and on most of the stelae in Sodo. Were these made to represent the human face, mainly eyebrow and nose (?) In the absence of satisfactory evidence pertinent to arrive at a plausible conclusion, there is a need to conduct further studies to see the existing similarities and differences among megalithic art in Africa particularly in the Horn.

Similar in their appearance with the above engraving at Odotibo are the ones on the stelae at Firshi and Gimise. However, they appear different for the branches are wider with geometric lines decorating them which give the impression that they could be representations of a certain plant probably of enset.

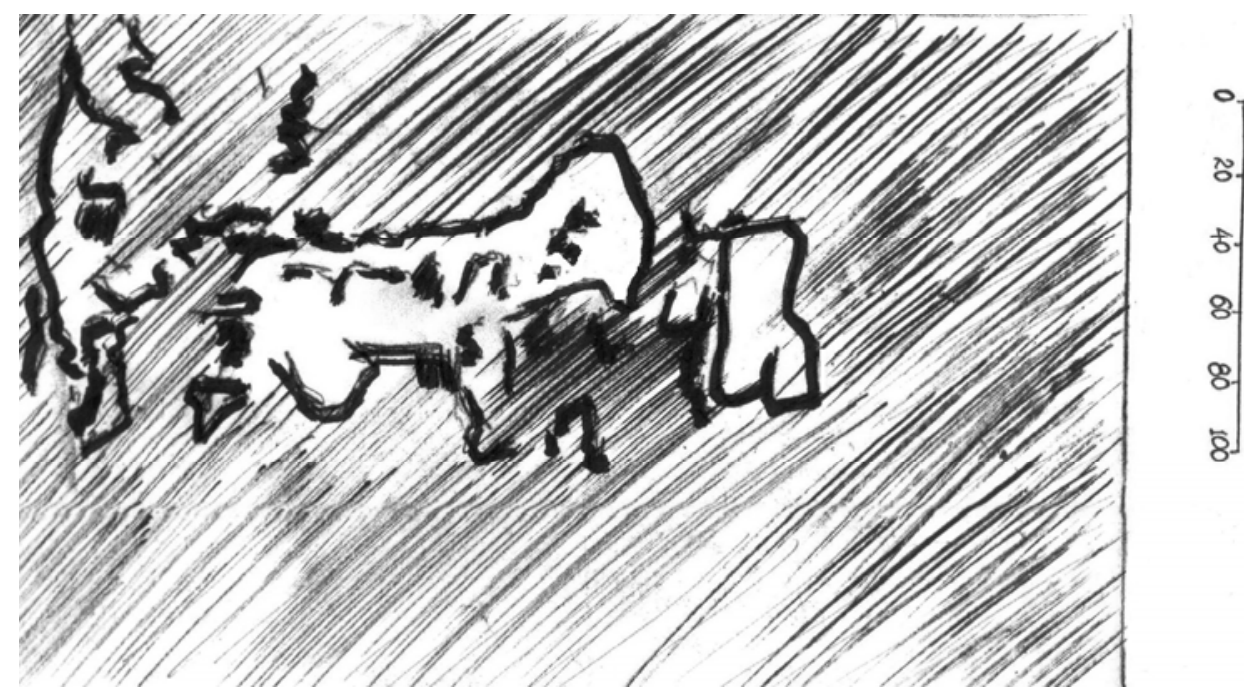

Figure 6: A Zoomorphic representation on stela No.1 at Gimise

Two types of megaliths were identified at Gimise. Of these clusters ${ }^{6}$ of stelae, the first group comprises two decorated stelae with damaged irregular distal edges. Both decorated stelae face to the southeast. The stela on the left is $53 \mathrm{~cm}$ in height and $83 \mathrm{~cm}$ in its width. In its present state, it is leaning on the western edge of the second stela to the right. This stela is unique for it is decorated with a zoomorphic engraving representing some pack animal, probably a horse. The edges of the stela are irregular due to a series of destructions as noticed from the scars left at the 
distal end and the left margin of the stela. Hence, the only frame on the right side is decorated with an engraving representing what resembles a branch of a tree (enset), which also appears on the second stela to the right ${ }^{8}$. It also consists of two enigmatic engravings, which require further investigation.

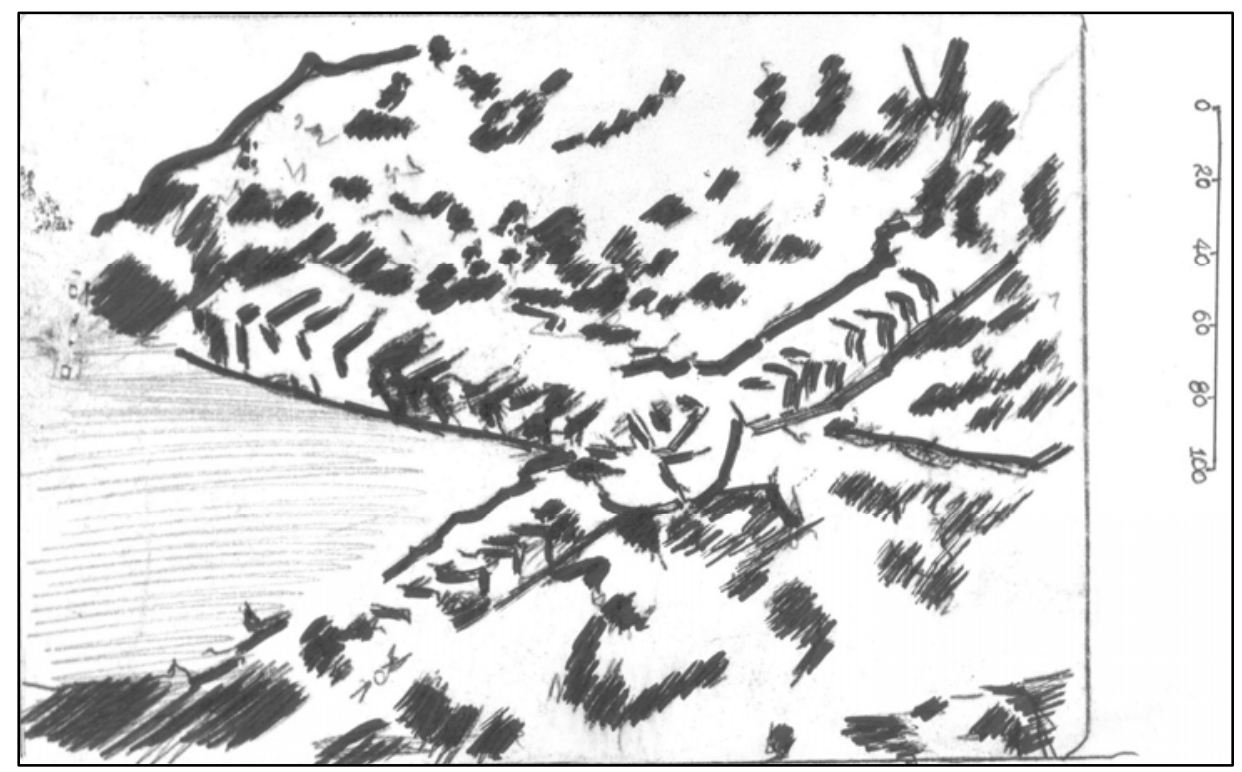

Figure 7: An engraving on two of the stelae at Locus A, Dubis1

Much different in the style of decoration is, the engraving in the form of $\mathrm{X}$ with circular disc at the center. It is engraved on stela №. 2 and stela №. 3 in group Two of Locus A at Dubis 1. In spite of the absence of ethnographic material comparable

6 The second type of megalithic structure at Gimise comprises of six stelae arranged in a circular pattern, much similar with those at Locus C of Dubis-1.They are visible for height ranging from $20 \mathrm{~cm}$ to $35 \mathrm{~cm}$. The all have broken edges characterized by irregularities.

7 The second stela to the right is $60 \mathrm{~cm}$ in height and $90 \mathrm{~cm}$ wide. It is similar with the first stela to the left, except the zoomorphic representation engraved on the face of the first stela to the left. Similar to the first stela, it has irregular distal edges largely destroyed at the left side. 
to this engraving; it has the appearance of the outer surface of a decorated shield. This could be an erroneous conclusion unless it is supported by other evidences.

Stela No. 2 of the first group within locus A at Dubis-1 and the single stela at Dubis-2 have analogous engravings with three rectangular representations radiating from a disc shaped engraving at the base. This could be interpreted as a representation of a shield and hence could probably have been used to mark the burial of a warrior. Yet, the individual carvings seen on the ventral part of the stelae generally appear to be depictions of wheat or sorghum, and the circular engraving at the base are likely to represent a loaf of bread. This would therefore be an indication of the presence of a farming community in the area.

By and large, it is plausible that the meaning of symbols requires extensive ethnoarchaeological studies involving careful examination of the material and culture of the people residing over the wider part of southern Ethiopia. It would therefore be a reckless attempt to define symbols without material evidence to support the validity of the data.

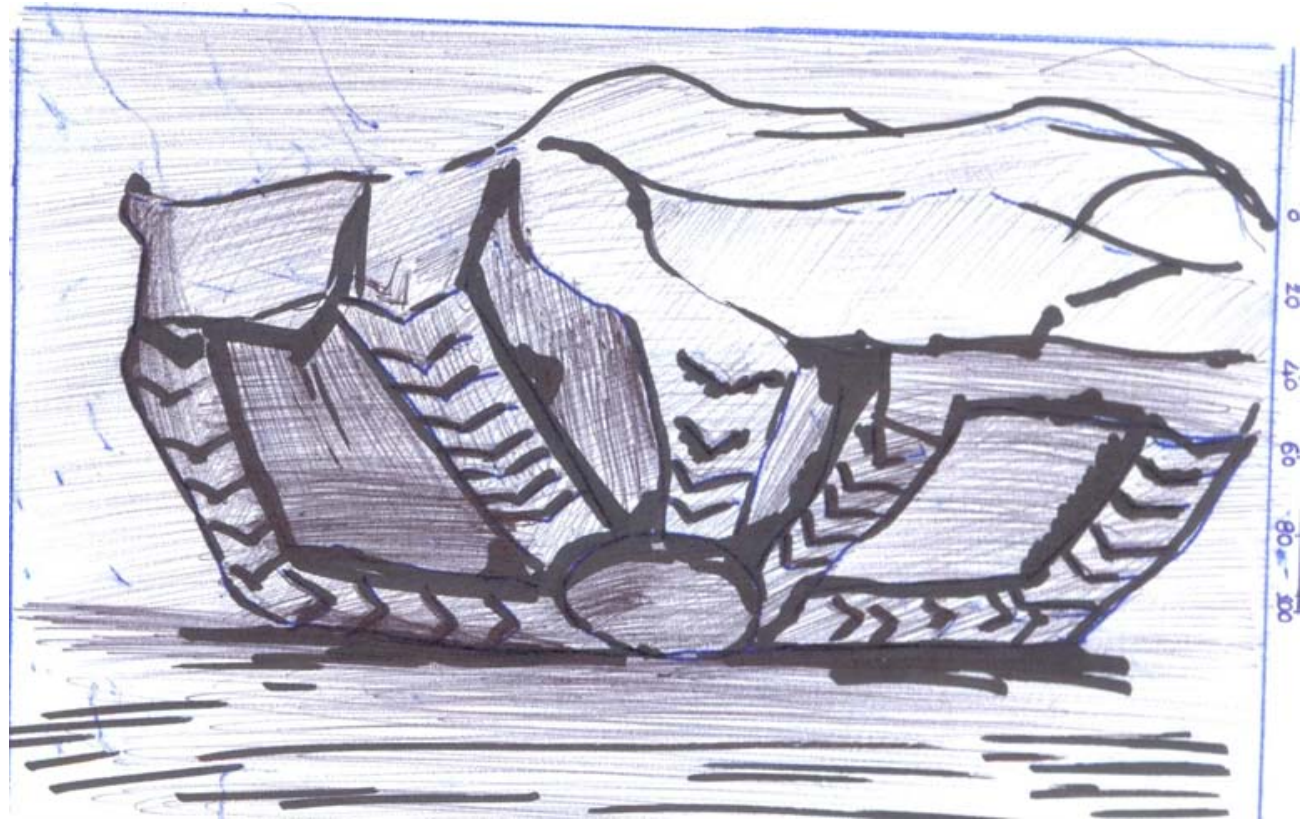

Figure 8: Engraving occurring on stelae at Locus A of Dubis 1 and at Dubis 2 


\section{The Enigma of Megalith Builders}

Although it is difficult to make confident inferences about the megalith builders in this part of Ethiopia, it seems appropriate to look into the difficulty related to it. In this regard, the available historical and linguistic evidences appear to be insufficient to arrive at a satisfactory conclusion.

Historical evidences suggest that the Sidama were the earliest inhabitants of the Shewan plateau (Taddese 1972). Shack (1966) also mentions the Sidama ${ }^{8}$ as people who also inhabited the area today occupied by the Gurage.

The only linguistic and conclusive evidence that seem to give insight on the problem related to the megalith builders revolves around the word Sodo ${ }^{9}$, which lacks a specific meaning in both Gurage and Oromo languages. The word also appears as a place name in the present Gurageland and Wolayta. However, whether these common place names suggest the presence in the area of a certain population who spoke the same or related languages in the past is not yet conclusive.

According to Anfray (1982), the word Sodo (also Sodicha or Sodiyu) in Sidama refers to standing stones. Thus, the lexical definition of the term in Sidama poses the question about whether the tradition had to do with the Sidama or not. Due to the scanty nature of the evidence, reliance on the meaning of a single word might lead to an erroneous conclusion unless supported by other lines of evidences. Apart from the historical and linguistic evidences, the available archaeological data show that the megalithic sites of Gatira Demma and Tiya date back to the $12^{\text {th }}$ century (Anfray 1982) and between the $11^{\text {th }}$ and $13^{\text {th }}$ century(Joussaume 1993;1995) respectively. The ages of these dated sites

\footnotetext{
${ }^{8}$ The presence of the Sidama in the area is supported by Taddesse (1972), who states that the military settlements established in this part of the country "were reported to have maintained their linguistic identity in a completely Sidama environment."

${ }^{9}$ Travelers of the $19^{\text {th }}$ century mention Sodo as a name of one of the Oromo clans settling along the Awash River (Anfray, 1982). In addition, Antoine D' Abbadie (1873) cited in Anfray (1982) lists Sodo as one of the sons born from Dache, a second wife of a man named Tulema. Except the mention of the word as a name of an Oromo clan and its appearance in the genealogical lines credited to Abadie, there has not been a single scholar who has attempted to relate the term within the context of the megalithic tradition in the area we now call Sodo. The term also appears as Soddu, which in Arsi Oromo refers to stelae. In other parts of Oromiya a closer term Sidaa is used to refer to stelae erected to mark a burial or ritual site. The similarity in the meaning of the word in both Sidama and Oromo languages seem to have emanated from the linguistic affinity within the Cushitic languages. However, there is a need to undertake further linguistic study on the etymology of the word.
} 
precede the period which historical accounts regard as a period of the establishment of military settlements in Gurageland. Thus, the Sidama are considered as antecedents of the Gurage and the Oromo living in the area. Even if, the scanty historical and linguistic evidences do not preclude the possibility, they are insufficient to state confidently that the Sidama are the possible candidates for the tradition under discussion. For a better understanding, however, there is a need to conduct further studies on the ethno-genesis of the Sidama. Attempts should also be made to examine the etymology of the word Sodo. Hence, archaeologists, anthropologists, historians and linguists should work together to come up with a research project that would shed light on the mystery behind the megalith builders.

\section{Remarks and Conclusion}

The study has resulted in the identification of twelve decorated stelae in sites located in Sodo, and twelve dressed but undecorated stelae in the district of MehurAklil. The stelae in Mehur-Aklil occur in varying shape as flat, rectangular, pentagonal and cylindrical. The stelae in the study areas also show variation in size ranging between $35 \mathrm{~cm}$ at Korechitin in Mehur- Aklil and $260 \mathrm{~cm}$ at Odotibo in Sodo.

The association of tambourines with a mound exhibiting stone structures at Locus B of Dubis - 1, and at Dubis- 5, suggest the sites might have had a funerary function though this needs to be supported by further archaeological investigation involving excavation.

The three decorated stelae at Odotibo, though in a fallen state, have no comparable parallel in the style of decorations they exhibit. These stelae are decorated with anthromorphic representations; daggers, decorations resembling reversed ' $W$ ' and circular disc like engravings. Similarly, the decorated stelae at Dubis - 1 show variation in the style of engravings but with some similarities within the site itself. However, remarkable inter-site similarities pertinent for discussion have not been noticed.

In spite of the existing differences in decoration, petrological examination has shown that the stelae east of Bui were made from the same type of rock i.e. Rhyolitic- ignimbrite, which can easily be shaped and hence is easier to work with. It is a white grayish rock obtained from Gefersa, the possible quarry located between the localities of Dubis and Odotibo. Though Gefersa does not exhibit concrete evidences about the use of the site as a quarry, the absence of such evidences as unfinished stelae and tools employed for quarrying do not preclude the possibility of the site having served as the source of raw materials.

Because of the frequent occurrence of lithic outcrops similar to the stelae in Mehur-Aklil, and the difficulty to sample rocks from the stelae, it is difficult to tell about the types of rocks used to carve the stelae. Yet, surface collections from the 
surrounding rocks have shown the possibility that the stelae might have been erected from trachytes occurring over most part of the surroundings. Nonetheless, this claim should be supported by further petrological examination on samples from the stelae at the sites.

From technological point of view, the perforations on the stelae at Odotibo and Dubis and the decorations engraved on the stelae at these sites and at Firshi and Gimise imply the use of metal implements. Above all, it is possible to infer from the engraving representing daggers and spearhead that the megalith builders were using weapons made of metal. Hence, the knowledge of making and using metal predate the erection of these groups of stelae.

The presence of a mosaic megalithic tradition represented by tambourines, decorated stelae and stelae erected underground is quite remarkable. However, it raises the question as to whether they represent similar cultural facies or not. Especially, the occurrence of stelae erected under ground and decorated stelae at Dubis - 1 seem to be a result of such factors as variation in technology, belief or even social status of the deceased. It is, therefore, difficult to make a conclusive remark but logical to infer that the decorated stelae might have been erected later than those undecorated stelae. It is owing to the difficulty to set up a relative chronology based on this typological variation. The logical evolutionary arrangement from crude to refined should of course be supported by concrete facts of relative or absolute dating. It is, therefore, the work of future archaeologists to come up with concrete archaeological evidences which would enable one to establish the chronology of the sites.

The study has revealed the presence of different symbols with the interpretations and problems related to each of the engravings. Thus, the megalith builders have also left us symbols engraved on the decorated stelae in Sodo. Some of these motifs and symbols have remained a point of discussion among archaeologists. The meaning entailed within symbols represented by engravings remains unknown due to the interruption or alteration in the material culture or ritual practices symbolized. Though absence is not a prerequisite for speculation, it is problematic and very uncertain to infer the meaning of symbols with out the presence of a living culture similar to or comparable with what the stelae exhibit.

Noting the possibilities of suggesting various interpretations, I believe that the anonymity behind symbols can be resolved through ethno-archaeological studies conducted on the material culture of the diverse communities living in Southern Ethiopia. It is also valuable to look into the evolution and relation of megalithic art in the Horn of Africa because of the long-standing contacts and cultural ties over centuries.

In discussing about the megalith builders, it is much difficult to reach conclusions as the available historical and linguistic evidences are inadequate to 
lead to a reliable explanation. Even so, the scanty evidences seem to suggest, though they are inadequate to state confidently that the Sidama were responsible for the tradition in this part of Ethiopia. However, note should be taken here that there is a need to follow a multi disciplinary approach involving archaeologists, anthropologists, historians and linguists to shed light on the enigmatic nature of engravings and megalith builders.

\section{Acknowledgement}

My warm words of praise go to Dr. Kassaye Begashaw, for his guidance and advice and Mr. David Chapple for editing the draft article. I also would like to express my gratitude to the anonymous reviewers of the article for their constructive comments

\section{References}

Abiyot Debebe. 2006.Archaeological Survey of Chalba-Tutti Megalithic Sites in Gedeo-Zone. Department of History, Archaeology Unit, M.A Thesis, Addis Ababa University.

Addisalem Melesse. 2009. An Ethnoarchaeological Study of Megalithic Tradition Among the Hadiya in Southern Ethiopia. Department of History, Archaeology Unit, M.A Thesis, Addis Ababa University.

Anfray, F.1982. "LES STELE du DUD SHOA et SIDAMO. ” In Annales D' Ethiopie,Vol.12(Gizaw Hilemariam's Amharic translation of Anfray's research on the stelae in Shoa and Sidamo), PP.9-42.

Bahn, P. 2001. The Penguin Archaeology Guide. London: Penguin Books Ltd. Crawford, O.G.S.1954. Archaeology in the Field. London: Phoenix House Ltd.

Brhan Teka. 2010. Archaeological Inventory of the Megalithic Sites of Aksum Vicinity and Shire Area. Department of History, Archaeology Unit, M.A Thesis, Addis Ababa University.

Ehret. C. 2002. The Civilizations of Africa: A History to 1800. University Press of Virginia. Charlotte Ville.

Joussaume, R.1974. LeMegalithisme en Ethiopie: Monument funerares Protohistoriques du Harar. Paris: C.N. R.S. .1976a. 'Les dolmens Ethiopiennes, AE 10:41-52. . 1987. Dolmens for the Dead: Megalith Building throughout the World. London: Bastford Lit. 
1993. "Le Megalithisme en Ethiopie: les objectifs d' une recherche", In Bulletin de la maison des Etudes Ethiopiennes, Addis Ababa, №_3. PP.5-15.

1995. Tiya-L' Ethiopie des Megalithes. Du biface 'a l'art rupestre dans la Corne de l'Afrique,Poitiers,P.117-165.

Merla, G.et. al.1979. A Geological Map of Ethiopia and Somalia. University of Florence. Renfrew, C. and Bahn,P.1996. Archaeology: Theories, Methods and practice. London: Thames and Hudson.

Muluneh Woldetsadik.1994. "Population Pressure, Land Use Change and Patterns of Agricultural Productivity in Ez'ana Wollene and Cheha Woredas Sebat bet Gurageland.”Department of Geography,M.A Thesis,Addis Ababa University

Shack, W.A. 1966. The Gurage : A people of Enset Culture. London: Oxford University Press.

Taddese Tamrat. 1972. Church and State in Ethiopia: 1270 - 1527. Oxford. Clarendon Press.

Tekle Hagos. 2001. "The Ethiopian Megalithic Culture."' In Kirs (A yearly published bilingual magazine). 1:47-55.

Willett, F. 1971. African Art. London: Thames and Hudson.

Yohannes Aytenew. 2008. "An Archaeological Study of the Megaliths of Atsbi Wemberta District and Its Environs.” Department of History, Archaeology Unit, M.A Thesis, Addis Ababa University. 